Article

\title{
3D-QSAR Study of Combretastatin A-4 Analogs Based on Molecular Docking
}

\author{
Yinghua Jin ${ }^{1}$, Ping Qi ${ }^{1,2}$, Zhiwei Wang ${ }^{2}$, Qirong Shen ${ }^{2}$, Jian Wang ${ }^{2}$, Weige Zhang ${ }^{2, *}$ and \\ Hongrui Song ${ }^{2, *}$
}

1 Department of Pharmacy, General Hospital of Beijing Military Command. Nanmencang No.5, Dongcheng District, Beijing 100700, China

2 School of Pharmaceutical Engineering, Shenyang Pharmaceutical University. No.103, Wenhua Road, Shenhe District, Shenyang 110016, Liaoning, China

* Authors to whom correspondence should be addressed; E-Mails: zhangweige2000@sina.com (W.Z.); hongruisong@163.com (H.S.).

Received: 14 June 2011; in revised form: 26 July 2011 / Accepted: 28 July 2011 /

Published: 8 August 2011

\begin{abstract}
Combretastatin A-4 (CA-4), its analogues and their excellent antitumoral and antivascular activities, have attracted considerable interest of medicinal chemists. In this article, a docking simulation was used to identify molecules having the same binding mode as the lead compound, and 3D-QSAR models had been built by using CoMFA based on docking. As a result, these studies indicated that the QSAR models were statistically significant with high predictabilities (CoMFA model, $\mathrm{q}^{2}=0.786, \mathrm{r}^{2}=0.988$ ). Our models may offer help to better comprehend the structure-activity relationships for this class of compounds and also facilitate the design of novel inhibitors with good chemical diversity.
\end{abstract}

Keywords: CA-4; antitumoral and antivascular activities; dock; CoMFA

\section{Introduction}

Combretastatin A-4 (CA-4) (Figure 1) was isolated from the bark of the South African tree Combretum caffrum in 1989 by Pettit and co-workers [1]. This cis-stilbene strongly inhibits tubulin polymerization by binding to the colchicine site and is found to be a cytotoxic agent against a wide variety of tumor cell lines, including multidrug-resistant lines [2,3]. The water-soluble sodium 
phosphate prodrug CA-4P (Zybrestat ${ }^{\mathrm{TM}}$ ) (Figure 1) is currently in several advanced clinical trials for age-related macular degeneration and anaplastic thyroid cancer based on the vascular shutdown mechanism of action $[4,5]$.

Figure 1. Combretastatin A-4 and its water-soluble sodium phosphate prodrug CA-4P.<smiles>COc1ccc(/C=C\c2cc(OC)c(OC)c(OC)c2)cc1O</smiles>

Combretastatin A-4 (1)<smiles>COc1ccc(/C=C\c2ccc(OC)c(OP(=O)([O-])O)c2)cc1OC</smiles>

Combretastatin A-4 phosphate

Due to its excellent antitumor and antivascular activities, CA-4 has attracted considerable interest of medicinal chemists in the design and preparation of analogs as novel antitumor agents. In the past 20 years, thousands of its analogs have been synthesized, and some CoMFA studies have been published [6,7]. These studies on the CA-4 analogues have revealed some detailed and instructional information on the effects of structural modification at several substitution positions. However, molecules used in previous CoMFA studies lacked molecular diversity because of their similar design ideas. Therefore, the obtained models might fail to predict other series of analogs.

For the purpose of achieving a more accurate CA-4 action model, CA-4 analogs were collected from different studies insamuch as possible. We envisaged that docking before CoMFA could help us identify which analogs have the same binding mode as CA-4. These selected molecules would then have chemical diversity, and a mode of action similar to that of CA-4.

When CoMFA is performed based on the docking alignment, we encountered a problem that the data from different sources are hard to compare and analyse. In other words, the values of CA-4 are not the same in different studies. The normalization method of processing data has been tested and the results prove its feasibility. Details are as follows: active value of CA-4 is set to 1, relative activity $=\mathrm{IC}_{50}$ (Compound)/ $\mathrm{IC}_{50}(\mathrm{CA}-4)$. When the compounds have activities higher than CA-4, the relative activities are less than 1 , and vice versa.

In this way, a kind of uniform comparability among the active value of different compounds from different studies has been built. At the same time, this normalization method provides a strong guarantee for our following 3D-QSAR study, and has laid a foundation for the design of new derivatives able to act as potent tubulin polymerization inhibitors.

\section{Methods}

\subsection{Data Sets}

The CA-4 analogues used for docking studies, with two-atom bridgeheads, were obtained from literature [8-30]. 


\subsection{Molecular Docking}

Molecular docking studies were performed with Molegro Virtual Docker 2008.3.0.0 to investigate possible binding modes for all studied compounds [31]. All parameters used in docking were the defaults. For example: the default radius of 10 was used. The grid resolution was $0.30 \AA$; the max iterations were 1,500; The max population size was 50 and the energy threshold was 100 .

\subsection{Molecular Modeling and Alignment}

All calculations were performed using SYBYL 6.91 on a Silicon Graphics Fuel workstation equipped with the IRIX 6.5 operating system [32]. Active conformation selection and molecular alignment are the most sensitive parameters to construct a more credible CoMFA model. However, at present, the crystal structure of this series of compounds has not been identified; therefore, docking alignment was used to construct the 3D-QSAR model.

\subsection{CoMFA Descriptors}

In this CoMFA study, the defaulting grid spacing of $2.0 \AA$ was used. A variable column filtering energy cutoff was set at $2.0 \mathrm{kcal} / \mathrm{mol}$ to enhance the signal-to-noise ratio. CoMFA calculates steric fields using a Lennard-Jones 6-12 potential and electrostatic fields using a Coulombic potential, and an $\mathrm{sp}^{3}$ hybridized carbon atom probe with a van der Waals radius of $1.52 \AA$ and a 1.0 charge was exploited in order to achieve the goal. Next, the model was optimized by setting steric and electrostatic field cutoffs at $30 \mathrm{kcal} / \mathrm{mol}$. The steric and electrostatic fields were scaled making use of the CoMFA-STD method in SYBYL $6.91[33,34]$. The partial least-squares (PLS) methodology, which is an extension of multiple regression analysis, was applied to derive the 3D-QSAR, employing CoMFA descriptor as independent variables, and $\mathrm{pIC}_{50}$ values as dependent variables. To measure the predictive ability of the derived model, the cross-validations conducted through the leave-one-out procedure was carried out to obtain the optimal number of components. Then the final non-cross-validated model was developed with an optimum number of components reported from the cross-validation results.

When the orientation of aligned molecules varied, the $\mathrm{q}^{2}$ value would change correspondingly. So the all-orientation search method (AOS) was executed by rotating the molecular aggregate within the grid to yield the highest $\mathrm{q}^{2}$ [35].

\section{Results and Discussion}

\subsection{Validation of the Molecular Docking Reliability}

CA-4 is a strong inhibitor of tubulin assembly by binding to the colchicine site, and in recent years, thousands of its analogues had been synthesized. There is no doubt that all of them have the same binding site as CA-4, yet these compounds exhibit different biological activities than CA-4. Therefore, we can reasonably assume that the binding capability to tubulin between them and CA-4 are not the same. In this study, we wished to identify the compounds which have the same binding modes as CA-4 through a docking study, followed by studies of their three-dimensional quantitative structure-activity relationships (3D-QSAR) to design a novel class of CA-4 mimics, capable of binding to the 
colchicine-binding site, displaying selective toxicity towards tumour vasculature and strongly inhibiting the tubulin polymerization.

We collected compounds from the literature [8-30] as docking objects, the common characteristics of which were that they were all linked by two-atom chain. For the purpose of checking the accuracy of the docking study, the ligand colchicine was extracted from the crystal structure of complex (PDB ID: 1sa0) [36] and re-docked in the colchicine-binding site of tubulin [37]. As a result, we found that the docking conformation corresponding to the lowest MolDockScore was nearly identical to that found in the original X-ray structure, with an acceptable RMSD of $0.7 \AA$ between the best scored conformation which obtained from docking and X-ray structure $1 \mathrm{sa} 0$ (Figure 2). Therefore, the Molegro Virtual Docker 2008.3.0.0 could be used for the following study.

Figure 2. Binding conformations of the docked colchicine (purple) and crystal colchicines (green) at the active site of tubulin.

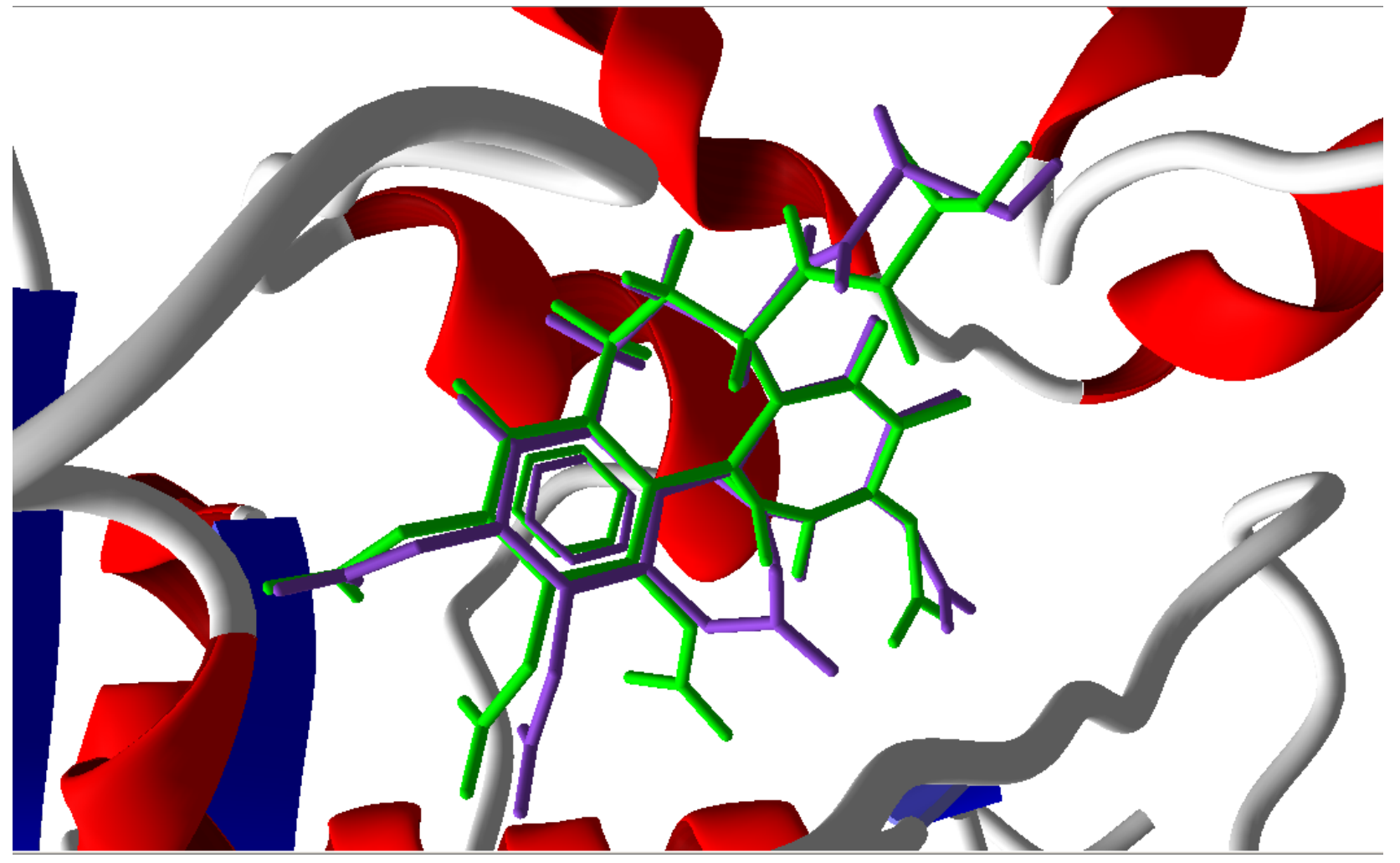

\subsection{Molecular Docking Results}

Since Molegro Virtual Docker can perfectly reproduce the reference binding modes observed in a crystal structure, it was used to dock all the ligands into the colchicine-binding site using the default parameters. The results of the docking study and visual analysis of the interactions suggested that among all studied compounds, there were 44 ligands whose binding modes were identical to that of CA-4. The structures of them were listed in Table 1. In the next step, we analyzed the docking scores for the 45 ligands. The lowest MolDockScore was selected and the values of them were listed in Table 2. However, only a low correlation was observed between docking scores and active values. This phenomenon, called false positive, is inevitable in any docking study [38]. The aligned compounds are shown in Figure 3. 
Table 1. Structures having the same binding modes as CA-4 and used in the training and test set.

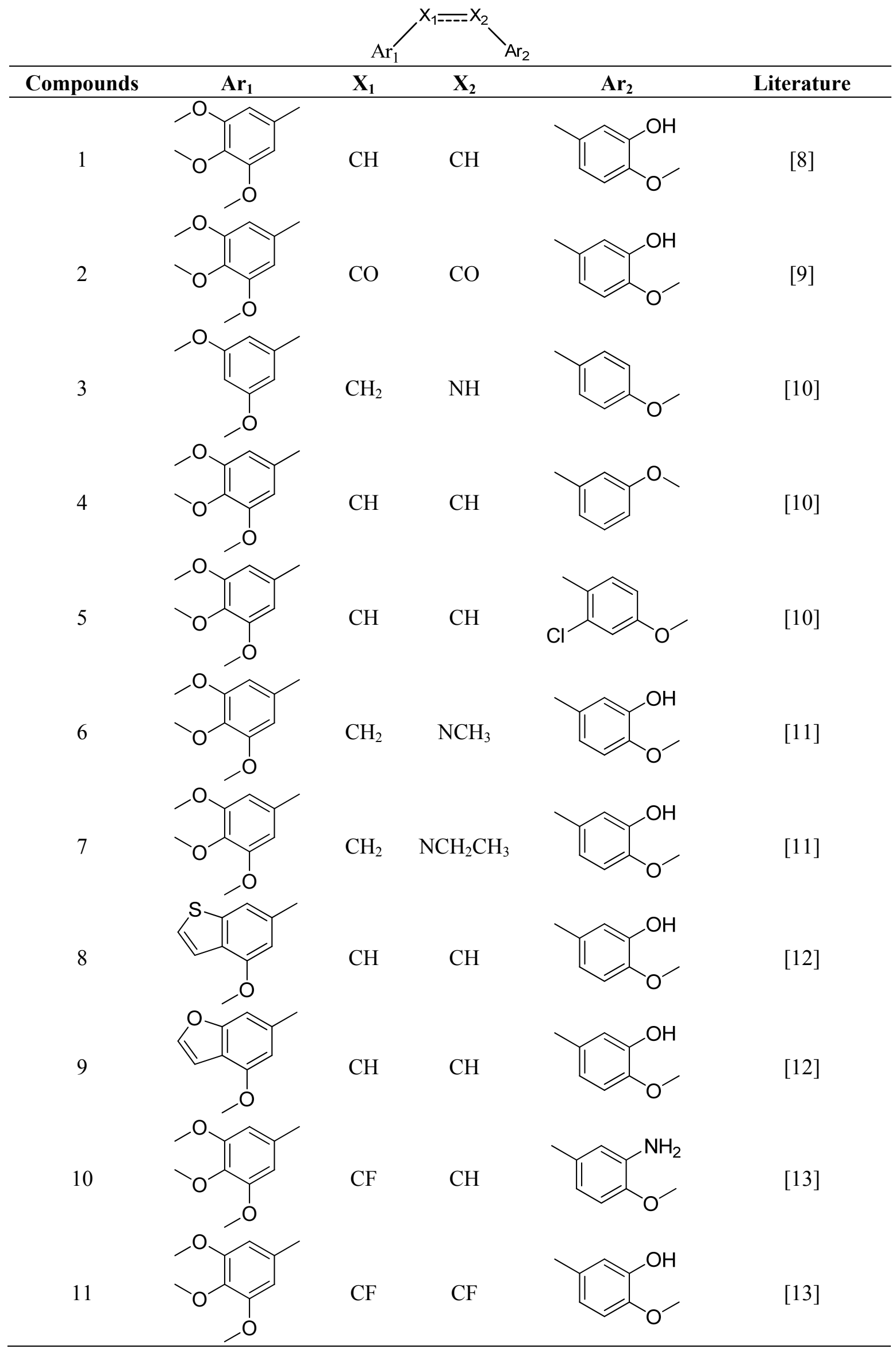


Table 1. Cont.

\begin{tabular}{|c|c|c|c|c|c|}
\hline Compounds & $\mathbf{A r}_{1}$ & $X_{1}$ & $X_{2}$ & $\mathbf{A r}_{2}$ & Literature \\
\hline 12 & & $\mathrm{CF}$ & $\mathrm{CH}$ & & [13] \\
\hline 13 & & $\mathrm{CH}_{2}$ & $\mathrm{CH}_{2}$ & & [14] \\
\hline 14 & & $\mathrm{CH}$ & $\mathrm{CH}$ & & [14] \\
\hline 15 & & $\mathrm{CH}$ & $\mathrm{CH}$ & & [15] \\
\hline 16 & & $\mathrm{CH}$ & $\mathrm{CH}$ & & [15] \\
\hline 17 & & $\mathrm{CH}$ & $\mathrm{CH}$ & & [15] \\
\hline 18 & & $\mathrm{CH}$ & $\mathrm{CH}$ & & [16] \\
\hline 19 & & $\mathrm{CCN}$ & $\mathrm{CH}$ & & [17] \\
\hline 20 & & $\mathrm{CH}$ & $\mathrm{CCN}$ & & [17] \\
\hline 21 & & $\mathrm{CCN}$ & $\mathrm{CH}$ & & [17] \\
\hline 22 & & $\mathrm{CH}$ & $\mathrm{CH}$ & & [18] \\
\hline
\end{tabular}


Table 1. Cont.

\begin{tabular}{|c|c|c|c|c|c|}
\hline Compounds & $\mathbf{A r _ { 1 }}$ & $\mathrm{X}_{1}$ & $\mathbf{X}_{2}$ & $\mathrm{Ar}_{2}$ & Literature \\
\hline 23 & & $\mathrm{CH}$ & $\mathrm{CH}$ & & [18] \\
\hline 24 & & $\mathrm{CH}$ & $\mathrm{CH}$ & & [18] \\
\hline 25 & & & & & [19] \\
\hline 26 & & $\mathrm{CH}$ & $\mathrm{CH}$ & & [20] \\
\hline 27 & & $\mathrm{CH}$ & $\mathrm{CH}$ & & [22] \\
\hline 28 & & & & & [21] \\
\hline 29 & & $\mathrm{CH}$ & $\mathrm{CH}$ & & [22] \\
\hline 30 & & $\mathrm{CHCN}$ & $\mathrm{CH}_{2}$ & & [22] \\
\hline 31 & & & & & [23] \\
\hline 32 & & & & & [23] \\
\hline 33 & & & & & [23] \\
\hline
\end{tabular}


Table 1. Cont.

\begin{tabular}{|c|c|c|c|c|c|}
\hline Compounds & $\mathbf{A r _ { 1 }}$ & $X_{1}$ & $\mathbf{X}_{2}$ & $\mathbf{A r}_{2}$ & Literature \\
\hline 34 & & & & & [23] \\
\hline 35 & & $\mathrm{CH}$ & $\mathrm{CH}$ & & [24] \\
\hline 36 & & $\mathrm{CH}$ & $\mathrm{CH}$ & & [25] \\
\hline 37 & & $\mathrm{CH}$ & $\mathrm{CH}$ & & [26] \\
\hline 38 & & $\mathrm{CH}$ & $\mathrm{CH}$ & & [26] \\
\hline 39 & & $\mathrm{CH}$ & $\mathrm{CH}$ & & [27] \\
\hline 40 & & $\mathrm{CH}$ & $\mathrm{CH}$ & & [27] \\
\hline 41 & & $\mathrm{CH}$ & $\mathrm{CH}$ & & [27] \\
\hline 42 & & $\mathrm{CH}$ & $\mathrm{CH}$ & & [27] \\
\hline 43 & & $\mathrm{CH}$ & $\mathrm{CH}$ & & [28] \\
\hline 44 & & & & & [29] \\
\hline
\end{tabular}


Table 1. Cont.

Compounds

Table 2. Relative activities, predicted activities and docking results for all studied compounds.

\begin{tabular}{|c|c|c|c|c|}
\hline Compound & Relative & Predicted & Residue & MolDockScore \\
\hline 1 & 0.00 & 0.03 & -0.03 & -92.11 \\
\hline $2^{t}$ & -0.18 & -0.08 & -0.10 & -102.1 \\
\hline 3 & -1.18 & -1.20 & 0.01 & -83.85 \\
\hline 4 & -0.67 & -0.68 & 0.01 & -86.39 \\
\hline 5 & -0.26 & -0.26 & -0.01 & -84.69 \\
\hline 6 & -1.06 & -1.02 & -0.04 & -81.16 \\
\hline 7 & -0.59 & -0.56 & -0.02 & -95.79 \\
\hline 8 & 0.23 & 0.18 & 0.05 & -84.34 \\
\hline 9 & -0.02 & -0.03 & 0.01 & -80.87 \\
\hline 10 & -0.05 & -0.02 & -0.03 & -117.5 \\
\hline 11 & -0.17 & -0.13 & -0.04 & -105.8 \\
\hline 12 & 0.29 & 0.21 & 0.08 & -103.8 \\
\hline $13^{t}$ & -0.26 & -0.21 & -0.05 & -88.41 \\
\hline $14^{t}$ & -0.26 & -0.06 & -0.19 & -90.39 \\
\hline 15 & 0.08 & 0.10 & -0.01 & -85.25 \\
\hline $16^{\mathrm{t}}$ & 0.05 & -0.12 & 0.17 & -82.73 \\
\hline $17^{\mathrm{t}}$ & 0.08 & -0.07 & 0.15 & -81.14 \\
\hline 18 & -0.10 & -0.09 & 0.00 & -94.13 \\
\hline 19 & -0.40 & -0.43 & 0.04 & -101.3 \\
\hline $20^{t}$ & -0.10 & -0.07 & -0.03 & -108.7 \\
\hline $21^{\mathrm{t}}$ & -0.18 & -0.44 & 0.27 & -101.9 \\
\hline 22 & 0.00 & 0.00 & 0.00 & -80.97 \\
\hline 23 & -0.18 & -0.15 & -0.03 & -84.11 \\
\hline $24^{t}$ & -0.18 & -0.08 & -0.09 & -95.84 \\
\hline 25 & -0.23 & -0.21 & -0.03 & -123.1 \\
\hline $26^{t}$ & -0.06 & -0.24 & 0.18 & -101.0 \\
\hline 27 & -0.48 & -0.49 & 0.01 & -105.3 \\
\hline 28 & -0.74 & -0.79 & 0.05 & -117.5 \\
\hline 29 & -0.78 & -0.80 & 0.02 & -110.2 \\
\hline 30 & -0.74 & -0.74 & 0.00 & -80.49 \\
\hline 31 & 0.24 & 0.20 & 0.05 & -120.4 \\
\hline $32^{t}$ & -0.37 & -0.59 & 0.23 & -126.9 \\
\hline 33 & 0.18 & 0.20 & -0.02 & -125.1 \\
\hline 34 & 0.11 & 0.16 & -0.04 & -118.4 \\
\hline 35 & -1.16 & -1.15 & -0.01 & -89.72 \\
\hline 36 & -0.14 & -0.14 & 0.00 & -83.71 \\
\hline 37 & 0.17 & 0.19 & -0.01 & -95.28 \\
\hline
\end{tabular}


Table 2. Cont.

\begin{tabular}{ccccc}
\hline Compound & Relative & Predicted & Residue & MolDockScore \\
\hline 38 & -0.92 & -0.95 & 0.03 & -88.45 \\
39 & 0.04 & 0.01 & 0.03 & -89.74 \\
40 & -0.73 & -0.72 & -0.01 & -113.6 \\
41 & -1.22 & -1.21 & -0.01 & -130.7 \\
$42^{\mathrm{t}}$ & -0.80 & -1.15 & 0.35 & -117.9 \\
43 & 0.00 & 0.04 & -0.04 & -90.15 \\
44 & 0.20 & 0.20 & 0.00 & -118.4 \\
45 & -0.32 & -0.33 & 0.00 & -91.68 \\
\hline
\end{tabular}

Figure 3. Alignment of all the studied compounds.

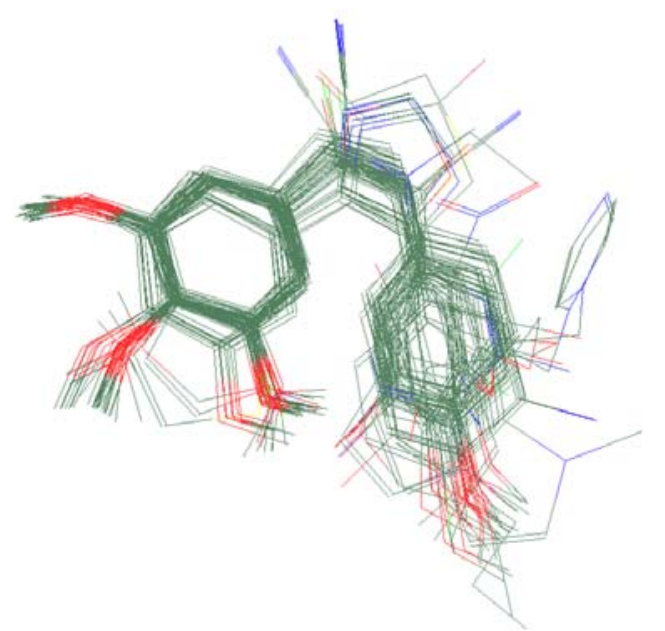

To further study the interaction between inhibitors and protein, the most potent compound 13 was selected to perform the deeper docking study (Figure 4) [39].

Figure 4. Interactions between the amino acids at colchicine-binding site and the most potent compound 13 .

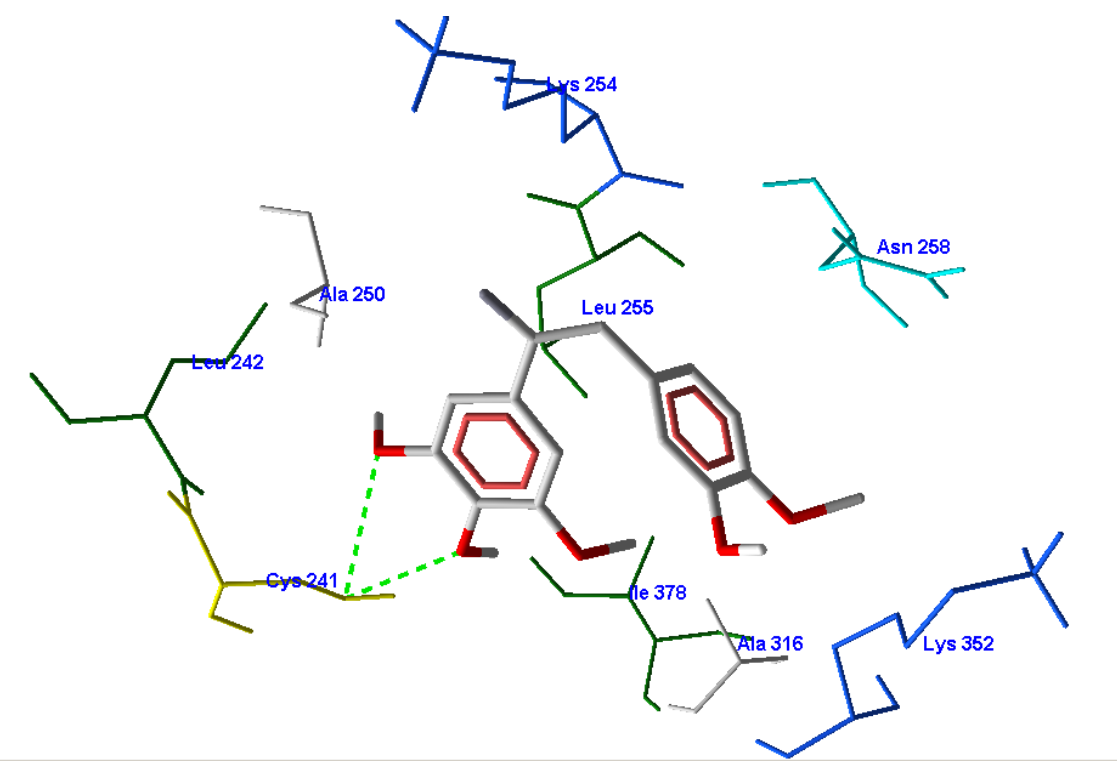


The meta- and para-methoxy $\mathrm{O}$ atoms of the A-ring can form a hydrogen bond with Cys241. A hydrophobic pocket created by Leu242, Leu255, Ala250 and Val318 was occupied by the trimethoxyphenyl, while the B-ring participated in the hydrophobic effect with Ala316, Lys352, Ile378 and Val315.

\subsection{CoMFA Results}

The CoMFA study was based on the docking data [40,41]. Alignment was conducted, giving $\mathrm{q}^{2}$ value of 0.540 . The optimum orientation was derived from AOS, with a satisfactory $\mathrm{q}^{2}$ value of 0.786 for five components. Using optimum number of components, the non-cross-validated PLS analysis was conducted to obtain an $\mathrm{R}^{2}$ value of $0.988, \mathrm{~F}$ value of 472.301 and a standard error of estimated (SEE) of 0.055 . The steric and electrostatic field descriptors represent $79.7 \%$ and $20.3 \%$ dedications, separately. In the Y-randomization validations, the $\mathrm{q}^{2}$ values are $-0.074,-0.241,-0.188,-0.059$, -0.075 ; and $\mathrm{r}^{2}$ values are $0.043,0.114,0.117,0.042$, and 0.067 . The low $\mathrm{q}^{2}$ and $\mathrm{r}^{2}$ values show that the good results in our original models are not due to a chance correlation or structural dependency of the training set. All mentioned above suggested that it is feasible to build the 3D-QSAR model through molecular docking alignment. Table 2 shows values with experimental $\mathrm{pIC}_{50}$, predicted $\mathrm{pIC}_{50}$ and the residues for all compounds. Figure 5 described the relationship between relative $\mathrm{pIC}_{50}$ and predicted $\mathrm{pIC}_{50}$. The data of CoMFA research are shown in Table 3.

Figure 5. Plot of relative and predicted activities for the training and test set compounds based on the CoMFA model.

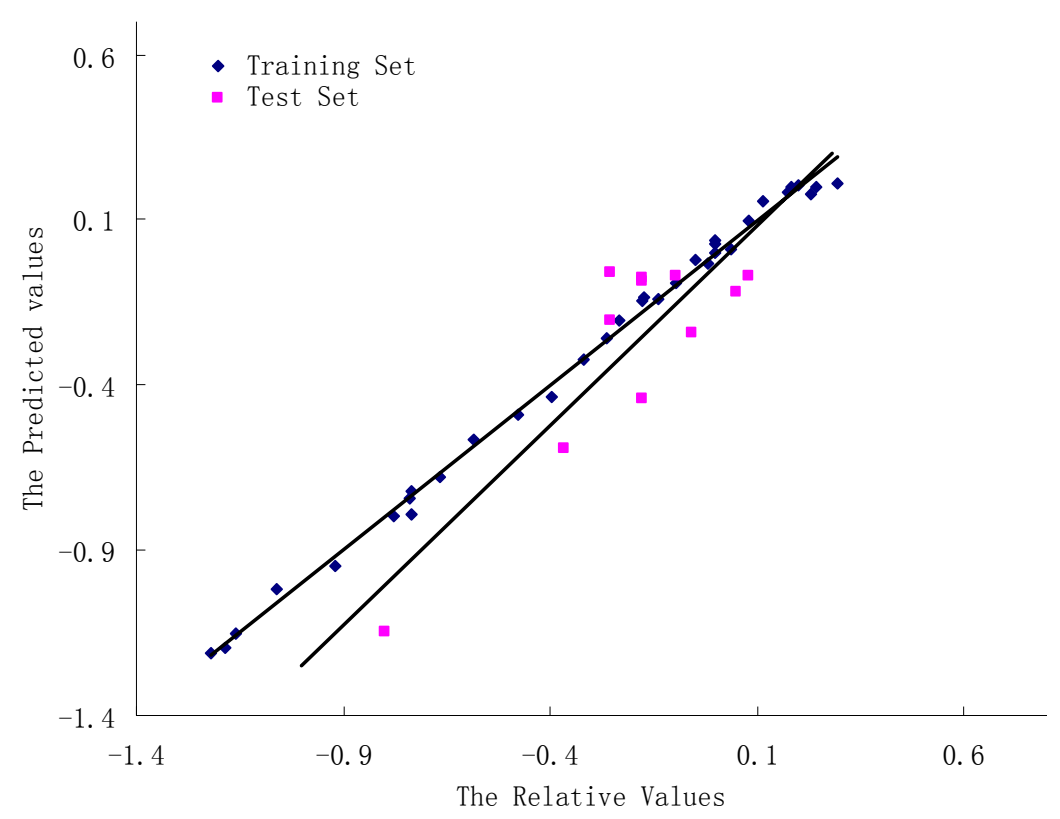

Table 3. Summary of the statistical parameters obtained from the CoMFA and analysis.

\begin{tabular}{ll}
\hline Statistical parameters CoMFA & CoMFA \\
\hline the number of training set compounds & 34 \\
\hline Components & 5 \\
$\mathrm{q}^{2}$ & 0.786 \\
Convention $\mathrm{r}^{2}$ & 0.988 \\
\hline
\end{tabular}


Table 3. Cont.

\begin{tabular}{ll}
\hline Standard error of estimated & 0.055 \\
F values & 472.301 \\
Predictive $\mathrm{r}^{2}$ & 0.7412 \\
Fraction & \\
Steric & $79.7 \%$ \\
Electrostatic & $20.3 \%$ \\
\hline
\end{tabular}

\subsection{Validation of the 3D-QSAR Models}

If models are reliable toward lead optimization, they must have convincing capability not only in interpolative accurateness but also in extrapolative confirmation [42]. The internal validation of leave-one-out cross validation has been confirmed by the value of $\mathrm{q}^{2}(0.786)$. However, as mentioned-above, a high value of $\mathrm{q}^{2}$ is not the necessary and sufficient condition for a QSAR model to have a better predictive power [43]. Therefore, an external validation was carried out on a set of 11 test compounds not involved in the training set to assess its forecasting ability. As a result, 11 compounds in the test set were all predicted well, with residuals within $1 \log$ unit. Moreover, the CoMFA model gave a good predictive $\mathrm{r}^{2}$ value of 0.7412 . The test results demonstrate that the CoMFA model we built can be useful in predicting the activities of newly designed inhibitors of tubulin polymerization.

\subsection{D-QSAR Contour Analysis}

The results gained from CoMFA model were graphically converted by means of the stdev*coefficient contour maps (Figure 6) to view the field impact on biological activity. These contour maps offer a more easier understanding of the binding mode of CA-4 analogues and remind us of any change in steric and electrostatic field in three-dimensional space may have effect on biological activity. The contour maps of CoMFA are described with the most potent inhibitors of tubulin assembly (compound 12).

As we can see from the CoMFA contour maps (Figure 6), steric factors influencing biological activity were expressed with green and yellow contour maps. A green region near of the A-ring reveals that bulky groups introduced in these positions are helpful for increasing activity. Compound 8 (0.23) with a thiophene-ring at C-3 and C-4 positions was a potent inhibitor of tubulin polymerization, the biological activity of which was even better than CA-4 (0). When replacing the thiophene-ring with a furan-ring (compound 9), the relative activity was -0.02 and decreased a little, and it was due to that fact the sulfur atom is bigger than an oxygen atom. Another bigger green contour behind the C-3 substituent of the B-ring highlights that larger groups are favorable to promote inhibitory ability, for instance, the biological activity of compound 39 (0.04) was a better than compound $30(-0.74)$. Two yellow contours are also shown in Figure 6. One was found above of the C-2 position of the B-ring, the other one was located at some distance from the two-atom chain. These yellow contours indicate that compounds bearing bulky groups in these regions would decrease the ability to inhibit tubulin polymerization. 
Figure 6. CoMFA STDEV*COEFF contour maps based on compound 12. Green contours emphasize areas that bulky groups are favorable, while yellow contours highlight regions that bulky substituents are unfavorable. Blue contours represent areas where electropositive substituents in these positions will enhance the inhibitory ability on tubulin polymerization while red contours emphasize regions where electronegative groups will increase the inhibitory activity.

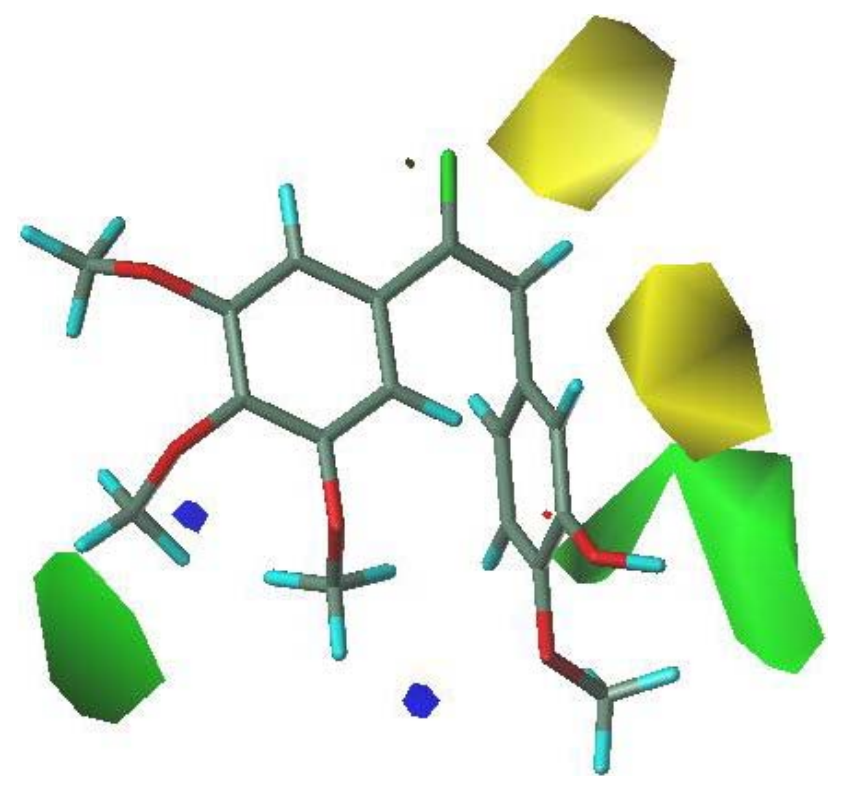

For compound $33(0.18$, Figure 7$)$, the oxazole moiety near the yellow contour would decrease the ability to inhibit tubulin polymerization, but the methyl group of the $\mathrm{N}$-methylindole moiety, which inserts into the green area near B-ring, can greatly increase the binding capability. In general, the molecules have the expected activity $(0.18)$.

Figure 7. CoMFA STDEV*COEFF contour maps based on compound 33 and CA-4 (1).

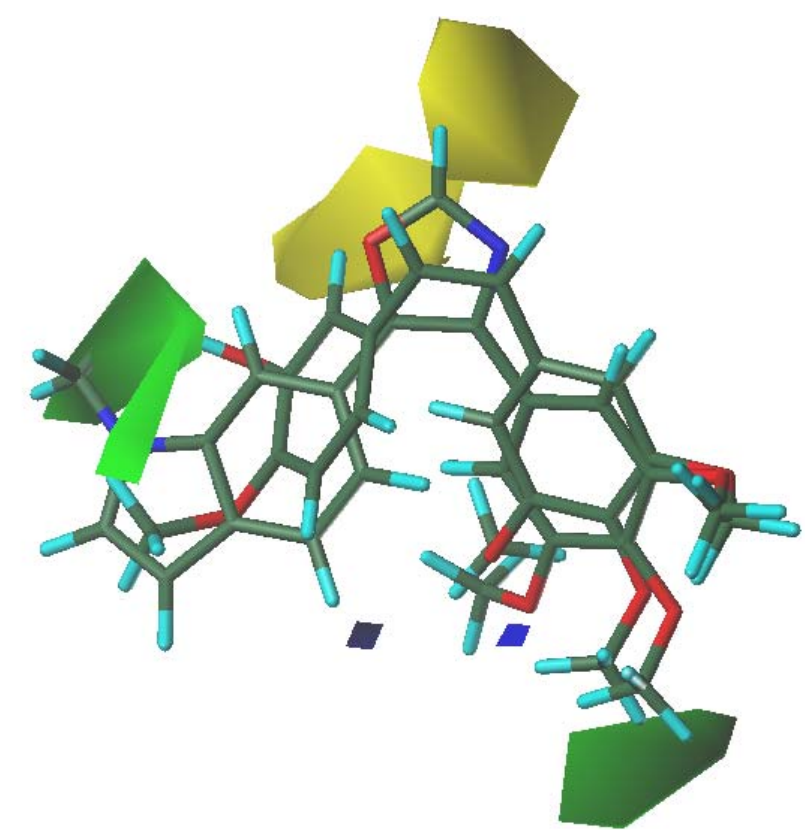


The electrostatic contour map shows two small blue contours in Figure 6. These blue contours indicate that compounds bearing electropositive groups, such as compound 15 (0.08), would increase the ability to inhibit the tubulin polymerization.

\section{Conclusions}

A study of molecular docking of CA-4 derivatives linked by a two-atom bridgehead was performed at the colchicine-binding site of tubulin. The binding modes of 45 compounds were identical to that of CA-4, and their interactions with tubulin were evaluated. On the basis of docking alignment, a satisfactory 3D-QSAR model was constructed, whose internal validation can be demonstrated by a $\mathrm{q}^{2}$ value of 0.786 , high value of $\mathrm{R}^{2}(0.988)$, and the external consistency that can be proved by the good predictive $\mathrm{R}^{2}(0.7412)$ for the test set. Moreover, the excellent statistical correlations and satisfactory predictive power suggest that it is feasible to build the 3D-QSAR model through molecular docking alignment. In this study, we also concluded: (1) as we can see from the CoMFA contour, the influence of the steric field was more important than that of the electrostatic field; (2) a green contour near the substituent at C-4 of the A-ring reminded us that introducing bulky groups at this position was helpful to enhance biological activity; (3) another bigger green contour behind of the C-3 substituent of the B-ring highlights that larger groups are favorable to promote inhibitory ability; (4) The two yellow contours that one is located above of the $\mathrm{C}-2$ position of the B-ring and another at some distance from the two-atom chain indicate that compounds bearing bulky groups at these regions would decrease the ability to inhibit the tubulin polymerization; and (5) higher electropositive moiety below the para-substituent of the A-ring is favorable to enhance the ability to inhibit the tubulin polymerization.

In summary, the results of the docking study and the analysis of 3D-QSAR provide much useful information for the rational design of novel inhibitors, capable of binding to the colchicine-binding site, displaying selective toxicity towards tumor vasculature and strongly inhibiting tubulin polymerization. Our models would offer help to better comprehend the structure-activity relationships of CA-4 compounds and also provide new solutions for drug design.

\section{Acknowledgments}

This work was partially supported by the National Natural Science Foundation of China (Grant No. 30973614) and National Science and Technology Major Project (Grant No.2009ZX09301-012).

\section{References}

1. Pettit, G.R.; Singh, S.B.; Hamel, E.; Lin, C.M.; Alberts, D.S.; Garcia-Kendall, D. Isolation and structure of the strong cell growth and tubulin inhibitor combretastatin A-4. Experientia 1989, 45, 209-211.

2. Lin, C.M.; Singh, S.R.; Chu, P.S.; Dempcy, R.O.; Schmidt, J.M.; Pettit, G.R.; Hamel, E. Interactions of tubulin with potent natural and synthetic analogs of the antimitotic agent combretastatin: A structure-activity study. Mol. Phamacol. 1988, 34, 200-208. 
3. Pettit, G.R.; Singh, S.G.; Boyd, M.R.; Hamel, E.; Pettit, R.K.; Schmidt, J.M.; Hogan, F. Antineoplastic agents. 291. Isolation and synthesis of combretastatins A-4, A-5, and A-6. J. Med. Chem. 1995, 38, 1666-1672.

4. Patterson, D.M.; Rustin, G.J.S. Combretastatin A-4 phosphate. Drugs Future 2007, 32, 1025-1032.

5. Lippert, J.W. Vascular disrupting agents. Bioorg. Med. Chem. 2007, 15, 605-615.

6. Liao, S.Y.; Chen, J.C.; Miao, T.F.; Shen, Y.; Zheng, K.C. Binding conformations and QSAR of CA-4 analogs as tubulin inhibitors. J. Enzyme Inhib. Med. Chem. 2010, 25, 421-429.

7. Ji, Y.B.; Tian, R.; Lin, W.H. QSAR and molecular docking study of a series of combretastatin analogues tubulin inhibitors. Lect. Notes. Comput. Sci. 2007, 4689, 436-444.

8. Flynn, B.L.; Flynn, G.P.; Hamel, E.; Jung, M.K. The synthesis and tubulin binding activity of thiophene-based analogues of combretastatin A-4. Bioorg. Med. Chem. Lett. 2001, 11, 2341-2343.

9. Mousset, C.; Giraud, A.; Provot, O.; Hamzé, A.; Bignon, J.; Jian, M.L.; Thoret, S.; Dubois, J.; Brion, J.D.; Alami, M. Synthesis and antitumor activity of benzils related to combretastatin A-4. Bioorg. Med. Chem. Lett. 2008, 18, 3266-3271.

10. Cushman, M.; Nagarathnam, D.; Gopal, D.; Chakraborti, A.K.; Lin, C.M.; Hamel, E. Synthesis and evaluation of stilbene and dihydrostilbene derivatives as potential anticancer agents that inhibit tubulin polymerization. J. Med. Chem. 1991, 34, 2579-2588.

11. Shirai, R.; Tokuda, K.; Koiso, Y.; Iwasaki, S. Synthesis and anti-tubulin activity of Aza-combretastatins. Bioorg. Med. Chem. Lett. 1994, 4, 699-704.

12. Simoni, D.; Romagnoli, R.; Baruchello, R.; Rondanin, R.; Grisolia, G.; Eleopra, M; Rizzi, M.; Tolomeo, M.; Giannini, G.; Alloatti, D.; et al. Novel A-ring and B-ring modified combretastatin A-4 (CA-4) analogues endowed with interesting cytotoxic activity. J. Med. Chem. 2008, 51, 6211-6215.

13. Alloatti, D.; Giannini, G.; Cabri, W.; Lustrati, I.; Marzi, M.; Ciacci, A.; Gallo, G.; Tinti, M.O.; Marcellini, M.; Riccioni, T.; et al. Synthesis and biological activity of fluorinated combretastatin analogues. J. Med. Chem. 2008, 51, 2708-2721.

14. Lin, C.M.; Singh, S.B.; Chu, P.S.; Dempcy, R.O.; Schmidt, J.M.; Pettit, G.R.; Hamel, E. Interactions of tubulin with potent natural and synthetic analogs of the antimitotic agent combretastatin: A structure-activity study. Mol. Pharmacol. 1988, 34, 200-208.

15. Pettit, G.R.; Minardi, M.D.; Rosenberg, H.J.; Hamel, E.; Bibby, M.C.; Martin, S.W.; Jung, M.K.; Pettit, R.K.; Cuthbertson, T.J.; Chapuis, J.C. Antineoplastic agents. 509. Synthesis of fluorcombstatin phosphate and related 3-Halostilbenes. J. Nat. Prod. 2005, 68, 1450-1458.

16. Monk, K.A.; Siles, R.; Hadimani, M.B.; Mugabe, B.E.; Freeland, A.J.; Studerus, S.W.; Edvardsen, K.; Trawick, M.L.; Garner, C.M.; Rhodes, M.R.; et al. Design, synthesis and biological evaluation of combretastatin nitrogen-containing derivatives as inhibitors of tubulin assembly and vascular disrupting agents. Bioorg. Med. Chem. 2006, 14, 3231-3244.

17. Ohsumi, K.; Nakagawa, R.; Fukuda, Y.; Hatanaka, T.; Morinaga, Y.; Nihei, Y.; Ohishi, K.; Suga, Y.; Akiyama, Y.; Tsuji, T. Novel combretastatin analogues effective against murine solid tumors: Design and structure-activity relationships. J. Med. Chem. 1998, 41, 3022-3032.

18. Hatanaka, T.; Fujita, K.; Ohsumi, K.; Nakagawa, R.; Fukuda, Y.; Nihei, Y.; Suga, Y.; Akiyama, Y.; Tsuji, T. Novel B-ring modifield combretastatin analogues: Synthesis and antineoplastic activity. Bioorg. Med. Chem. Lett. 1998, 8, 3371-3374. 
19. Flynn, B.L.; Flynn, G.P.; Hamelb, E.; Jungc, M.K. The synthesis and tubulin binding activity of thiophene-based analogues of combretastatin A-4. Bioorg. Med. Chem. Lett. 2001, 11, 2341-2343.

20. Chang, J.Y.; Yang, M.F.; Chang, C.Y.; Chen, C.M.; Kuo, C.C.; Liou, J.P. 2-amino and 2'-aminocombretastatin derivatives as potent antimitotic agents. $J$. Med. Chem. 2006, 49, 6412-6415.

21. Gurjar, M.K.; Wakharkar, R.D.; Singh, A.T.; Jaggi, M.; Borate, H.B.; Shinde, P.D.; Verma, R.; Rajendran, P.; Dutt, S.; Singh, G.; et al. Synthesis and evaluation of 4/5-Hydroxy-2,3diaryl(substituted)-cyclopent-2-en-1-ones as cis-restricted analogues of combretastatin A-4 as novel anticancer agents. J. Med. Chem. 2007, 50, 1744-1753.

22. Cushman, M.; Nagarathnam, D.; Gopal, D.; He, H.M.; Lin, C.M.; Hamel, E. Synthesis and evaluation of analogs of (Z)-1-(4-methoxyphenyl)-2-(3,4,5-trimethoxyphenyl)ethene as potential cytotoxic and antimitotic agents. J. Med. Chem. 1992, 35, 2293-2306.

23. Wang, L.; Woods, K.W.; Li, Q.; Barr, K.J.; McCroskey, R.W.; Hannick, S.M.; Gherke, L.; Credo, R.B.; Hui, Y.H.; Marsh, K.; et al. Potent, orally active heterocycle-based combretastatin A-4 analogues: Synthesis, structure-activity relationship, pharmacokinetics, and in vivo antitumor activity evaluation. J. Med. Chem. 2002, 45, 1697-1711.

24. Pettit, G.R.; Grealish, M.P.; Jung, M.K.; Hamel, E.; Pettit, R.K.; Chapuis, J.C.; Schmidt, J.M. Antineoplastic agents. 465. Structural modification of resveratrol: Sodium resverastatin phosphate. J. Med. Chem. 2002, 45, 2534-2542.

25. Pettit, G.R.; Anderson, C.R.; Herald, D.L.; Jung, M.K.; Lee, D.J.; Hamel, E.; Pettit, R.K. Antineoplastic agents. 487. Synthesis and biological evaluation of the antineoplastic agent 3,4-methylenedioxy-5,4'-dimethoxy-3'-amino-Z-stilbene and derived amino acid amides. J. Med. Chem. 2003, 46, 525-531.

26. Maya, A.B.S.; Pérez-Melero, C.; Mateo, C.; Alonso, D.; Fernndez, J.L.; Gajate, C.; Mollinedo, F.; Peláez, R.; Caballero, E.; Medarde, M. Further naphthyl combretastatins. An investigation on the role of the naphthalene moiety. J. Med. Chem. 2005, 48, 556-568.

27. Pettit, G.R.; Rhodes, M.R.; Herald, D.L.; Hamel, E.; Schmidt, J.M.; Pettit, R.K. Antineoplastic Agents. 445. Synthesis and Evaluation of Structural Modifications of (Z)-and (E)-Combretastatin A-4. J. Med. Chem. 2005, 48, 4087-4099.

28. Ohsumi, K.; Nakagawa, R.; Fukuda, Y.; Hatanaka, T.; Morinaga, Y.; Nihei, Y.; Ohishi, K.; Suga, Y.; Akiyama, Y.; Tsuji, T. Novel combretastatin analogues effective against murine solid tumors: Design and structure-activity relationships. J. Med. Chem. 1998, 41, 3022-3032.

29. Kaffy, J.; Pontikis, R.; Carrez, D.; Croisy, A.; Monneret, C.; Florent, J.C. Isoxazole-type derivatives related to combretastatin A-4, synthesis and biological evaluation. Bioorg. Med. Chem. 2006, 14, 4067-4077.

30. Simoni, D.; Romagnoli, R.; Baruchello, R.; Rondanin, R.; Rizzi, M.; Pavani, M.G.; Alloatti, D.; Giannini, G.; Marcellini, M.; Riccioni, T.; et al. Novel combretastatin analogues endowed with antitumor activity. J. Med. Chem. 2006, 49, 3143-3152.

31. Thomsen, R.; Christensen, M.H. MolDock: A new technique for high-accuracy molecular docking. J. Med. Chem. 2006, 49, 3315-3321.

32. SYBYL. Molecular Modelling System, version 6.9.1; Tripos Inc.: Saint-Louis, MS, USA, 2003.

33. Teixeira, C.; Serradji, N.; Maurel, F.; Barbault, F. Docking and 3D-QSAR studies of BMS-806 analogs as HIV-1 gp120 entry inhibitors. Eur. J. Med. Chem. 2009, 44, 3524-3532. 
34. Lu, P.; Xia, W.; Zhang, R. CoMFA and CoMSIA 3D-QSAR Studies on quionolonecaroxylic acid derivatives inhibitors of HIV-1 integrase. Eur. J. Med. Chem. 2010, 45, 1-7.

35. Wang, R.; Gao, Y.; Liu, L.; Lai, L. All-orientation search and all-placement search in comparative molecular field analysis. J. Mol. Model. 1998, 4, 276-283.

36. Ravelli, R.B.G.; Gigant, B.; Curmi, P.A.; Jourdain, I.; Lachkar, S.; Sobel, A.; Knossow, M. Insight into tubulin regulation from a complex with colchicine and a stathmin-like domain. Nature 2004, 428, 198-202.

37. He, Y.Z.; Li, Y.X.; Zhu, X.L.; Zhen, X.; Niu, C.W.; Wan, J.; Zhang, L.; Yang, G.F. Rational design based on bioactive conformation analysis of pyrimidinyl benzoates as acetohydroxy acid synthase inhibitors by integrating molecular docking, CoMFA, CoMSIA, and DFT calculations. J. Chem. Inf. Model. 2007, 47, 2335-2344.

38. Böhm, H.J.; Stahl, M. Reviews in Computational Chemistry; Lipkowsky, K.B., Boyd, D.B., Eds.; John Wiley \& Sons: Hoboken, NJ, USA, 2002; pp. 41-87.

39. Liao, S.Y.; Chen, J.C.; Miao, T.F.; Shen, Y.; Zheng, K.C. Binding conformations and QSAR of CA-4 analogs as tubulin inhibitors. J. Enzyme Inhib. Med. Chem. 2010, 25, 421-429.

40. Hu, R.; Barbault, F.; Delamar, M.; Zhang, R. Receptor- and ligand-based 3D-QSAR study for a series of non-nucleoside HIV-1 reverse transcriptase inhibitors. Bioorg. Med. Chem. 2009, 17, 2400-2409.

41. Hu, R.J.; Barbault, F.; Maurel, F.; Delamar, M.; Zhang, R.S. Molecular dynamics simulations of 2-Amino-6-arylsulphonylbenzonitriles analogues as HIV inhibitors: Interaction modes and binding free energies. Chem. Biol. Drug Des. 2010, 76, 518-526.

42. Qiong, X.X.; Mei, D.Z.; Fei, P.B.; Yang, L.; Hong, J.R.; Jian, W.; Sheng, M.C. CoMFA, CoMSIA and eigenvalue analysis on dibenzodioxepinone and dibenzodioxocinone derivatives as cholesteryl ester transfer protein inhibitors. Molecules 2008, 13, 1822-1839.

43. Golbraikh, A.; Tropsha, A. Beware of q ${ }^{2} . J$. Mol. Graph. Model. 2002, 20, 269-276.

Sample Availability: Samples of the compounds are not available from the authors.

(C) 2011 by the authors; licensee MDPI, Basel, Switzerland. This article is an open access article distributed under the terms and conditions of the Creative Commons Attribution license (http://creativecommons.org/licenses/by/3.0/) 